\title{
Changing dynamics in female employment
} around childbirth: evidence from Germany, the Netherlands and the UK

\section{- Jan Dirk Vlasblom \\ Utrecht University \\ I Joop Schippers \\ Utrecht University}

\begin{abstract}
There is a strong effect of childbirth on female labour supply. This effect, however, is changing over time. This article uses panel data on the last two decades on three European countries (the Netherlands, Germany, the UK) to study changes in female labour force behaviour around childbirth and tries to find an explanation for these changes by looking at differences between the three countries. We conclude that there are substantial differences in participation patterns between the three countries in our study and that policy measures and institutions such as childcare that make the costs of combining work and family lower relative to being a full-time mother seem to increase female participation rates.
\end{abstract}

\section{KEY WORDS}

family policies / female labour supply / institutions / transitions / work-life balance

\section{Introduction}

n existing literature on both fertility and female labour supply it has been shown that there is a strong interdependency between the presence of children in the household and female labour supply. Women with children tend to work less than those without children. In many of these studies a crosssectional approach has been used to show the differences in labour supply 
behaviour. In this article we will explicitly study the dynamics of labour supply around childbirth.

After childbirth, women can choose to remain in full-time work. They can also lower their number of working hours in order to facilitate the combination of work and family life, or they can leave the labour market, either permanently or for a limited period (mostly, until the children reach school age). The choice between these three types of participation is highly influenced by individual preferences and by the restrictions women (or households) face. Mertens showed that, at least in the Netherlands, over the total life cycle these decisions lead to three 'dominant' patterns (Mertens, 1998). The first pattern is that women leave the labour market after the birth of the first child, have more children and do not return to work. The second pattern is that women have only one child and work both before and (shortly) after childbirth. The third, less common, pattern is the one in which women have two children, work before the first birth, return to work after the birth of the second child, with an interruption between the first and the second child. Interview-based research for the Netherlands also showed that the choice between these three major patterns is closely related to the division of care tasks between husband and wife, which usually emerge shortly after the birth of a new baby and appear to persist throughout early childhood (De Jong and De Olde, 1994). This is why the moment of birth of a first child is not only a major event in the parents' personal life. It is also a major event from the point of view of the mother's labour market career.

As no complete life-cycle data are available for our research, this article focuses on the individual transitions from labour to care activities around childbirth and tries to answer the question of the extent to which women succeed in maintaining a tie with the labour market during different stages of family formation. Among others, Joshi et al. (1996) have shown that losing this tie is detrimental for women's human capital and, as a consequence, for women's future earnings and career possibilities. Even a small tie (e.g. through part-time work) diminishes the depreciation of human capital and thereby reduces the risk of poverty and social exclusion. We present analyses for three European countries: for the Netherlands and (West) Germany over the period 1985 to 2000, and for the UK over the period 1991 to 2000. We try to identify the effect of major institutional and policy changes on female labour supply by relating within-country changes in labour supply over time to changes in national institutions.

\section{Labour market transitions around childbirth}

There exists an extensive literature on individual and household decisionmaking with respect to labour supply both from an economic and from a more sociological point of view. Starting with Becker's 'New Home Economics', part of the economic literature also goes into the issue of decision-making within the 
household (Becker, 1965). Next to economic incentives, the decision to work is also affected by attitudes to work and family (Crompton and Harris, 1998a, 1998b; Hakim, 1998; Marks and Houston, 2002).

Households that face a decision on labour market participation will make a trade off between the costs and the benefits of participation. Labour market participation of the household members will generate benefits: the income needed to maintain a standard of living for the household, but it will also result in costs. The less time partners have available for household work, the more activities have to be outsourced, which is costly. When a child is born new duties and tasks emerge and most households have to reconsider the division of their activities. The balance between costs and benefits may shift due to the new situation. The potential earnings of both partners, and thus the benefits of labour market participation, will not change, but the level of household work, and therefore the opportunity costs of participation increase considerably as household size increases. The time needed for childcare increases in particular. It is therefore expected that a number of former two-earner households become one-earner households at the birth of the first child. However, withdrawal from the labour market may have serious long-term effects: total withdrawal from the labour market will seriously hamper future entrance, or will have strong effects on the earnings after a future return to work. If these effects are larger, or the household places a large weight on this effect in their decision, the probability that a woman will not stop working will be greater.

The effect of economic incentives may depend on norms and values. Both Hakim, (1998, 2000: 6, Table 1.1) and Van der Lippe and Siegers (1994) stress the intermittent character of norms on individuals' reactions to economic incentives. Households that strongly oppose working mothers will not be strongly influenced by large decreases in potential future earnings, as the woman will not return. Households that are in favour of equal role-sharing will not be very influenced by economic incentives, as the woman will stay in the labour market. The group in between, labelled as adaptives by Hakim (1995, 1996, 1998, 2000), will be the most responsive to possible short- and long-term effects of their decisions, as their norms do not fully determine their behaviour.

In explaining labour supply behaviour by attitudes and norms, the question can be raised as to whether or not attitudes towards certain behaviour are fixed and predetermined. Hakim states that preferences towards work determine the career that women have. Those preferring not to work will act accordingly, while others, having strong orientations towards work, will choose to work. These women may not have children at all. The adaptives will first make a career and eventually try to combine this with children. Hakim argues that behaviour follows attitudes, while others argue that to some extent, attitudes follow behaviour (Crompton and Harris, 1998a, 1998b). Finally, some argue that there is a far more complicated interaction between individual norms, group norms and behaviour, allowing feedback from one to the other (Vendrik, 1993, 2003). However, in all three cases there is a causality from attitudes towards behaviour, at least in the short run. 
The participation decision is partly based on a cost-benefit analysis by the household. Benefits of working are related to the human capital of the woman. The higher her educational level and the more labour market experience she has, the higher her potential income will be. On the other hand, the costs of working are more or less fixed. Of course, individuals with higher human capital may require childcare of higher standards, which is more expensive. Also, due to payment schemes, the costs of childcare may be partly dependent on income, but in general costs are more related to the provider of the services than to the buyer of these services. This implies that the opportunity costs of not participating in the labour market are relatively high for women with high human capital, while they have relatively low direct costs. For women with little human capital, the opposite holds. Therefore, we expect that withdrawal from the labour market at childbirth is more common for less-educated women, while highly-educated women continue work (although, perhaps, at a lower number of weekly hours). At second childbirth, the same holds. However, there will also be women who stop working, because staying in the labour market will not compensate for the increased costs of children. The birth of a second child may, for instance, result in the necessity of substituting relatively cheap informal childcare, by more expensive, formal childcare. This may hold especially for women with lower levels of education who decide to keep working when their first child is born.

In our empirical analysis we face the problem of not having any direct information on women's attitudes towards work for the Dutch as well as the German data. Therefore, we have to use imperfect, more implicit information on these attitudes. Lommerud and Vagstad label careers that focus more on the family than on paid work as the 'mummy track', and a career that is more focused on paid work than on the family by a 'market career track' (Lommerud and Vagstad, 2000). The women in the first track one are more family-oriented, while the women in the second are more modern in their attitudes and more work-oriented. Not only is the participation decision related to these attitudes, but it is also known that women who are more modern have children at a later age. Also, women who are more modern often choose to cohabit instead of marrying. Therefore, we use age at first birth and marital status as an imperfect proxy of orientations towards work. We therefore expect that women having their first child relatively early will not return to work, while women having their first birth relatively late will not interrupt (Gustafsson et al., 1996). Also, as non-married cohabiting women tend to have 'more modern' norms, we expect them to have a higher probability of working and staying in the labour market after childbirth than married women.

The spacing between two subsequent children may also relate to the pattern: women having their children within a short spell of time will be facing a combination of problems that may be more severe for a short duration. Again, economic motives and orientations towards work are interrelated: we expect career-oriented women to have their children close together and women having 
children shortly after each other to have a greater probability of not interrupting their careers.

Labour market behaviour around birth differs according to birth order of the child, and by the preferred number of children. The tendency to stay at home for a longer period will be higher if the woman wants another child, even when this child is not yet born. Also, the tendency to return to the labour market will be higher when the family has reached its preferred size. Here, two observations may be relevant. The first is that women opting for a relatively large family will withdraw from the labour market. As soon as the first child is born, they choose to specialize in household activities. When this tendency for specialization increases with the preferred number of children, the fall in participation rates will be greater for women with more children. The second observation is that women who do not return to the labour market shortly after the first birth may have problems in returning at a later moment in time. These increasing problems can be explained by the depreciation of human capital and increasing search costs. Also, employers may interpret the length of the interruption period as a signal that these mothers are not very committed to the labour market and paid work (Roman and Schippers, 2005). When return to the labour market is not possible, the opportunity costs of having another child are relatively low. In that case, the career interruption is the explanation for the relatively large number of children.

So far, we have discussed factors women can influence, to a certain extent, through their own choices. However, women may be restricted in realizing their preferences by the economic situation in a given period. When unemployment rates are high, it may be unwise to leave a paid job. This may result in a larger number of women who keep working in times of high unemployment. When unemployment is high, women who are already out of the labour market may find it more difficult to return. So, our hypothesis is that high local unemployment rates are detrimental to transitions, both into and out of the labour market.

Moreover, the institutional context may create strong incentives for a woman to choose a given pattern. Therefore, differences between countries in return patterns and return speed can be related partly to institutions (Wetzels, 1999). When taxes are such that one-earner households are favoured, women may choose non-participation. When they want to work, but there is no affordable childcare available or leave schemes are insufficient, they are forced to leave the labour market. Following Hakim, it can be expected that not all women will react to the institutional setting in the same way and magnitude (Hakim, 2003: 237-45).

Although a number of women keep working after childbirth, they may reduce working hours in order to combine work and family tasks. In the Netherlands a reduction of working hours is often possible without a change of job, and part-time work is well protected and not necessarily in the secondary labour market. As a result of this, part-time work in the Netherlands provides a stable labour market situation, while in Germany and the UK part-time work 
is not a fully-fledged option, but often a 'second best' solution (Anxo et al., 2000; Bothfeld and O'Reilly, 2000; Hendrickx et al., 2001). Although the situation in Germany and the UK is steadily improving, in the period under study the situation was different. In Germany a legal right for part-time work was introduced in January 2001. In the UK, in 2003, a right to flexible working was established. However, this is outside the period covered by our data. Although Hakim (1995) stresses the fact that women chose part-time jobs, there is also evidence that a number of women in part-time jobs want to change their labour market position (Walsh, 1999; Walters, 2005; Warren, 2004). Due to these differences in the nature of part-time work we do not present part-time work as an independent fourth strategy in addition to the three strategies presented in the introduction.

\section{Empirical analysis of the transition patterns}

For our analysis we use panel data: the Institute of Labour Studies (OSA) database for the Netherlands, covering the period 1983 to 1998, the German Socio-Economic Panel (GSOEP) covering the period 1984 to 2000 for (West) Germany and the British Household Panel Survey (BHPS) for the UK, covering the period 1991 to 2001. All three databases contain information on an individual basis, giving relatively detailed information on family formation and labour market participation. From this data we selected all women who gave birth to a child within the sample period, as labour market information was not sought retrospectively. We used participation figures on a monthly basis over the period 24 months before and 24 months after birth. Due to the exact phrasing of the questions, there are differences between the three countries in the period shortly after birth: in the BHPS and the GSOEP women can report their status as 'on leave'. In the Dutch questionnaire, they do not have that option. So, even though almost all Dutch women take up their statutory sixteen weeks of pregnancy/maternity leave they report themselves as 'working for pay' in this period. The category of mothers with three or more children is left out of the analyses because of relatively small numbers: there were 204, 171 and 269 third births in the Dutch, German and British data, respectively.

In Table 1 we illustrate the process of change in labour supply by showing average participation rates in the period around childbirth, starting two years before and ending two years after childbirth. For the Netherlands, the measurement error mentioned above is evident in the very large percentage of women working in the month of birth.

Table 1 shows that in all three countries, participation rates drop considerably around childbirth. Women in the Netherlands and the UK lower their participation rates before birth, even in their 'pre-pregnancy periods' so there is clearly an anticipation effect. After childbirth the patterns in the countries differ markedly. In the Netherlands, participation rates keep falling and in the six months after birth, the average rate in the Netherlands falls by 
two children is minimal: two years after the last birth, average participation levels of women with one child only are 57 percent, while the rate of those with two children reaches 54 percent.

In the remainder of this section we will estimate a model to explain the differences in these patterns, and to relate these patterns to the characteristics of the women. Ideally, the question on return to the labour market should be answered using duration models. However, as a result of the way participation is recorded around childbirth, it is not possible to determine the length of the interruption exactly. To overcome this problem, we use a multinomial logit model to analyse the effects of the various factors that may explain women's participation patterns around childbirth. To do so we define a transition by comparing the labour market status six months before birth to the status 12 months afterwards. This results in four possible transitions around childbirth: work before and after birth (YY), work before, but not after birth (YN), not working before, but working after birth (NY) and not working before and after birth (NN). In Table 2 the frequencies of these transitions are presented.

We include the educational level as indicator for human capital. Of course, human capital consists of more than initial education (e.g. Portela, 2001), but other aspects such as total work experience and individual ability are not included in our data. As discussed before, attitudes towards work tend to influence participation decisions. In our data, however, direct information with respect to attitudes to work is lacking. In all three databases there is some information available with respect to various aspects of the current job, but these relate to 'job satisfaction' or characteristics that a job has/should have and not to the 'attitudes to work' (i.e. the role work plays in your life) as used by, for example, Hakim. Therefore, we have to use very crude proxies in our empirical specification. Age at first birth is included as indicator for the career-orientedness of the woman. Marital status at the time of birth is included as it is also expected to be an indicator of attitudes since nonmarried couples tend to have more equal sharing of tasks in and outside the

Table 2 Patterns around childbirth, 6 months before - 12 months after birth, in \%a)

\begin{tabular}{|c|c|c|c|c|c|c|}
\hline & \multicolumn{2}{|c|}{ The Netherlands } & \multicolumn{2}{|l|}{ Germany } & \multicolumn{2}{|c|}{ United Kingdom } \\
\hline & $\begin{array}{l}\text { Around } \\
\text { first birth }\end{array}$ & $\begin{array}{l}\text { Around } \\
\text { 2nd birth }\end{array}$ & $\begin{array}{l}\text { Around } \\
\text { first birth }\end{array}$ & $\begin{array}{l}\text { Around } \\
\text { 2nd birth }\end{array}$ & $\begin{array}{l}\text { Around } \\
\text { first birth }\end{array}$ & $\begin{array}{l}\text { Around } \\
\text { 2nd birth }\end{array}$ \\
\hline YY & 40 & 29 & 25 & 17 & 32 & 27 \\
\hline YN & 33 & 6 & 55 & 22 & 24 & 10 \\
\hline NY & 3 & 5 & 2 & 5 & 17 & 19 \\
\hline NN & 24 & 56 & 18 & 57 & 27 & 44 \\
\hline \# observations & 543 & 520 & 649 & 506 & 668 & 592 \\
\hline
\end{tabular}

a) Children born after 1980 in the Netherlands, after 1983 in Germany and after 1990 in the United Kingdom. Source: OSA 1985-1998/GSOEP 1984-2000/BHPS 199|-2001 
home compared to married couples. We also include a dummy variable indicating that the observed birth is the last birth observed. Because we do not have data on the complete life cycle, we interpret this as an indicator of completed fertility. However, using this variable, the factor 'completed fertility' is measured with relatively large error, especially for the younger respondents. For the second birth we also include the spacing between children. Finally, regional unemployment rate at the moment of childbirth is included as an indicator of the economic circumstances. For this rate, the unemployment rate as provided by Eurostat at NUTS-1 level is used. Unfortunately, there is no suitable measure for the degree in which government policy and institutional arrangements favour the combination of paid work and family life (Koopmans and Schippers, 2003). Reliable measures for the supply or actual use are lacking when it comes to, for instance, childcare facilities. What we do see in most countries, or at least in the countries included in this study, is an extension of work-family arrangements (either public or private) over time (Den Dulk, 1999). Even though in one country the emphasis may be more on changing tax rules, while in another country the policy focus is on leave or childcare facilities, the overall picture is that welfare state regimes have become more 'friendly' towards the reconciliation of work and family life. Therefore, we include year of birth of the child to see whether or not there tend to be any systematic changes in transition patterns over time. These changes over time, in turn, can be related to changes in social norms and the institutional context. We also tried a more flexible, non-linear specification. This, however, did not improve the fit of the model.

Many of the relevant factors in the participation decision are choice factors such as educational level, number and timing of children, and the participation decision. These factors may be interrelated, which may cause some endogeneity. However, the choices are made in a distinct order, and these choices are, at least to some extent, irreversible. Therefore, the educational level is predetermined when it comes to the fertility and the participation decision. The educational level in turn determines the moment women enter into marriage and motherhood (Blossfeld and Huinink, 1991), because women in full-time education are not supposed to enter into marriage and motherhood (i.e. the role models of a student and partner are conflicting). Therefore, it may be argued that the number and timing of children are to a large degree predetermined when deciding on participation.

The estimated parameters of the logit model can be found in Table 3 for the transitions around first birth and in Table 4 for the transitions around second birth. As can be seen, there are a number of similarities between countries and between birth orders. It should also be noted that the model does not perform as well for the UK as it does for the other two countries. An explanation could be that due to institutional restrictions, women in the UK have few options, and therefore their behaviour does not differ between women of different characteristics as much as it does in the other two countries. 
Table 3 Estimated parameters of the multinomial logit model explaining participation patterns around first birth, the Netherlands, Germany and the United Kingdom

\begin{tabular}{|c|c|c|c|c|c|c|c|c|c|}
\hline \multirow[b]{2}{*}{ Variable } & \multicolumn{3}{|c|}{ The Netherlands } & \multicolumn{3}{|l|}{ Germany } & \multicolumn{3}{|c|}{ United Kingdom } \\
\hline & $Y N$ & NY & NN & YN & NY & NN & $Y N$ & NY & NN \\
\hline \multirow[t]{2}{*}{ Constant } & $15.126 * *$ & 4.522 & $16.674 * *$ & $-6.939 * *$ & 2.081 & -3.848 & 1.153 & $-13.108^{*}$ & 3.572 \\
\hline & $(5.25)$ & $(0.54)$ & $(5.37)$ & $(2.77)$ & $(0.27)$ & $(1.19)$ & $(0.23)$ & $(2.16)$ & $(0.74)$ \\
\hline \multirow[t]{2}{*}{ Age at first birth } & $-0.073^{*}$ & -0.088 & $-0.165^{* *}$ & 0.005 & $-0.289 * *$ & $-0.074^{*}$ & $-0.055^{*}$ & $-0.046^{*}$ & $-\left.0.14\right|^{* *}$ \\
\hline & $(2.29)$ & $(1.19)$ & $(4.70)$ & $(0.21)$ & $(2.83)$ & $(2.16)$ & $(2.55)$ & $(1.98)$ & $(6.10)$ \\
\hline \multirow[t]{2}{*}{ Low educated } & $0.817^{* *}$ & -0.955 & $1.233^{* * *}$ & 0.015 & 1.357 & $1.137 *$ & 0.462 & 0.347 & $0.870 * *$ \\
\hline & $(2.86)$ & $(0.87)$ & $(4.11)$ & $(0.03)$ & $(1.50)$ & $(2.44)$ & $(1.34)$ & $(0.83)$ & $(2.67)$ \\
\hline \multirow[t]{2}{*}{ High educated } & $-1.275^{* *}$ & 0.053 & $-0.7 \mid 4^{*}$ & $-0.663 * *$ & $1.557^{*}$ & 0.064 & -0.249 & 0.402 & -0.137 \\
\hline & $(3.94)$ & $(0.08)$ & $(2.00)$ & $(2.90)$ & $(1.98)$ & $(0.21)$ & $(1.02)$ & $(1.57)$ & $(0.54)$ \\
\hline \multirow[t]{2}{*}{ Last child } & -0.508 & 0.783 & 0.166 & -0.180 & 0.940 & -0.134 & $-0.515 *$ & -0.019 & 0.037 \\
\hline & $(1.82)$ & $(1.25)$ & $(0.56)$ & $(0.87)$ & $(I .4 I)$ & $(0.50)$ & $(2.14)$ & $(0.07)$ & $(0.15)$ \\
\hline \multirow[t]{2}{*}{ Birth year of child } & $-0.145^{* *}$ & -0.077 & $-0.147^{* *}$ & $0.093^{* *}$ & 0.001 & 0.053 & -0.011 & $0.125^{*}$ & -0.012 \\
\hline & $(4.99)$ & $(0.92)$ & $(4.68)$ & (3.52) & $(0.02)$ & $(1.54)$ & $(0.2 \mathrm{I})$ & (2.09) & $(0.24)$ \\
\hline \multirow{2}{*}{ Non-married } & $-2.342 * *$ & 0.533 & -0.760 & -0.108 & 1.031 & 0.896 ** & 0.289 & -0.238 & 0.379 \\
\hline & $(3.62)$ & $(0.80)$ & $(1.80)$ & $(0.43)$ & $(1.52)$ & $(3.14)$ & $(1.18)$ & $(0.86)$ & $(1.55)$ \\
\hline \multirow{2}{*}{ Unemployment rate } & 0.003 & 0.205 & 0.028 & -0.080 & 0.109 & 0.047 & $0.151 *$ & $0.216 * *$ & 0.101 \\
\hline & $(0.06)$ & $(1.34)$ & $(0.46)$ & $(1.91)$ & $(0.86)$ & $(0.88)$ & $(2.18)$ & $(2.65)$ & $(1.52)$ \\
\hline Log likelihood & \multicolumn{3}{|c|}{-527.0} & \multicolumn{2}{|c|}{-626.5} & \multicolumn{4}{|c|}{-842.4} \\
\hline \# observations & \multicolumn{2}{|c|}{543} & & \multicolumn{2}{|c|}{649} & & \multicolumn{2}{|c|}{668} & \\
\hline
\end{tabular}

$t$-values in parenthesis: * significant at $5 \%, * *$ significant at $1 \%$.

Source: OSA 1985-1998/ GSOEP |984-2000/BHPS |99|-2001 
Table 4 Estimated parameters of the multinomial logit model explaining participation patterns around second birth, the Netherlands, Germany and the United Kingdom

\begin{tabular}{|c|c|c|c|c|c|c|c|c|c|}
\hline \multirow[b]{2}{*}{ Variable } & \multicolumn{3}{|c|}{ The Netherlands } & \multicolumn{3}{|l|}{ Germany } & \multicolumn{3}{|c|}{ United Kingdom } \\
\hline & $Y N$ & NY & NN & YN & NY & $N N$ & $Y N$ & NY & $N N$ \\
\hline \multirow[t]{2}{*}{ Constant } & $|\mathrm{I} .6 \mathrm{I}| *$ & $18.177^{* *}$ & $20.06 I^{* *}$ & -1.435 & -0.197 & 5.292 & 6.408 & -5.727 & $10.226^{*}$ \\
\hline & $(2.22)$ & $(3.42)$ & $(6.07)$ & $(0.40)$ & $(0.03)$ & $(1.73)$ & $(0.97)$ & $(0.95)$ & $(2.15)$ \\
\hline \multirow[t]{2}{*}{ Age at first birth } & -0.075 & $-0.160 *$ & -0.063 & -0.065 & $-0.147 *$ & -0.042 & -0.021 & -0.051 & $-0.062 * *$ \\
\hline & $(1.24)$ & $(2.33)$ & $(1.90)$ & $(1.53)$ & $(2.09)$ & $(1.16)$ & $(0.6 I)$ & $(1.78)$ & (2.59) \\
\hline \multirow[t]{2}{*}{ Low educated } & 0.237 & 0.633 & $0.919 * *$ & -0.226 & -0.059 & 0.082 & -0.883 & -0.499 & $0.84 I^{* *}$ \\
\hline & $(0.45)$ & $(1.26)$ & $(3.14)$ & $(0.39)$ & $(0.07)$ & $(0.17)$ & $(1.49)$ & $(I .12)$ & $(2.76)$ \\
\hline \multirow[t]{2}{*}{ High educated } & -0.659 & -1.269 & $-1.286 * *$ & $-0.78 I^{*}$ & -1.139 & $-1.107^{* *}$ & -0.500 & 0.019 & -0.356 \\
\hline & $(1.26)$ & $(1.80)$ & $(4.39)$ & $(2.3 \mathrm{I})$ & (I.79) & $(3.82)$ & $(1.43)$ & $(0.07)$ & $(1.45)$ \\
\hline \multirow[t]{2}{*}{ Last child } & 0.229 & $1.292^{*}$ & 0.298 & 0.234 & 0.263 & 0.005 & -0.458 & 0.165 & -0.472 \\
\hline & $(0.47)$ & $(2.10)$ & $(1.10)$ & $(0.63)$ & $(0.46)$ & $(0.02)$ & $(I .2 I)$ & $(0.48)$ & (I.78) \\
\hline \multirow[t]{2}{*}{ Birth year of child } & $-0.115 *$ & $-0.168 * *$ & $-0.194 * *$ & 0.048 & 0.059 & -0.022 & -0.048 & 0.073 & -0.069 \\
\hline & $(2.18)$ & $(3.14)$ & $(5.88)$ & (I.28) & $(0.94)$ & $(0.68)$ & $(0.73)$ & $(1.24)$ & $(\mathrm{I} .47)$ \\
\hline \multirow[t]{2}{*}{ Non-married } & 0.350 & -0.204 & -0.068 & -0.352 & -1.176 & -0.472 & 0.237 & -0.098 & 0.333 \\
\hline & $(0.42)$ & $(0.18)$ & $(0.13)$ & $(0.65)$ & $(1.01)$ & $(0.98)$ & $(0.60)$ & $(0.29)$ & $(1.23)$ \\
\hline \multirow[t]{2}{*}{ Unemployment rate } & -0.095 & -0.100 & -0.020 & $-0.125^{*}$ & -0.098 & -0.003 & -0.167 & -0.023 & -0.129 \\
\hline & $(0.85)$ & $(0.89)$ & $(0.31)$ & (1.99) & $(0.94)$ & $(0.06)$ & $(1.73)$ & $(0.26)$ & $(1.83)$ \\
\hline \multirow[t]{2}{*}{ Spacing } & $-0.04 I$ & -0.230 & -0.092 & 0.007 & $-0.567^{* *}$ & $-0.148 * *$ & -0.122 & -0.022 & $-0.097^{*}$ \\
\hline & $(0.5 \mathrm{I})$ & $(1.60)$ & $(1.8 I)$ & $(0.14)$ & $(3.21)$ & (3.0I) & $(1.70)$ & $(0.47)$ & $(2.30)$ \\
\hline Log likelihood & \multicolumn{2}{|c|}{-442.2} & & \multicolumn{2}{|c|}{-516.3} & \multicolumn{4}{|c|}{-701.0} \\
\hline \# observations & \multicolumn{2}{|c|}{520} & & \multicolumn{2}{|c|}{506} & \multicolumn{4}{|c|}{592} \\
\hline
\end{tabular}


The effect of human capital is in all cases as expected. For all countries and birth orders it can be seen that compared to women with intermediate levels of education, women with low levels tend to decide for the YN- or the NN-pattern, while highly educated women opt for the YY-pattern and less frequently for the YN-pattern and the NN-pattern. The only exception is the group of highly educated women in Germany at first birth. They opt more frequently for a pattern of NY compared to women educated to intermediate level. Apparently, there is a group of highly educated women who choose to become mothers before entering the labour market. This effect is absent at second birth. Compared to the Netherlands and Germany, educational level has only a little effect on the dynamics around childbirth in the UK.

Age at first birth, interpreted as a measure for the degree of career orientation of the woman, also shows the expected effect. Both at first and second birth, women who have their first child at a relatively late age choose the YYpattern more frequently. A child being the last child does not affect the transition patterns very much, although this can perhaps be due to a measurement error in this variable. British women who have only one child tend to stop work less frequently than women with more children. In the Netherlands, the second child being the last child slightly increases the probability of return to the labour market after the second birth.

The estimation results show that the transition patterns around first birth differ according to marital status. In the Netherlands the results are as expected and non-married women tend to choose the YY-strategy more frequently than the YN-strategy. In Germany, the picture is slightly different and unmarried women opt for the NN-pattern, and less frequently for the YN-pattern. This points in the direction of a difference in labour supply in the pre-birth period. Married women are more likely to work before birth than unmarried women. We have no explanation for this finding. In the UK, unmarried mothers tend to stop work. When this is interpreted in terms of 'orientations to work', the effects do not match our expectations, as non-married women are expected to show a higher tendency to return to work after birth. Perhaps this is due to the fact that the outcome of the process of decision-making with respect to marriage is a very crude and imperfect proxy for work orientations. The effect of being unmarried is not present at second birth, which is also due to the fact that the percentage of mothers still unmarried at second birth is very small.

The spacing between children has little effect in the Netherlands but in Germany and the UK the effect is greater. In both countries, a larger space between the first and the second child results in a greater probability of the YYpattern occurring. Here our hypothesis is not confirmed since we expected a shorter space between births to result in a greater probability of the YY-pattern. Apparently, it is possible to have a second child and still combine work and family, as long as the oldest child is not too young. Instead of the duration of the period with small children, it is the 'intensity' of this period that appears to be the most important factor. 
The economic situation in the year of birth has only a small effect and there are no effects in the Netherlands or in Germany. In the UK, the estimations show the opposite effect to that anticipated. When unemployment rates are higher, job mobility around childbirth seems to increase. This may be due to a labour demand effect. Combining work and family life is difficult and in times of high unemployment employers will be reluctant to provide for arrangements that facilitate the combination of work and care for children. If a mother decides to leave work, employers can easily find a replacement. This mechanism is stronger in the UK, where workers are more dependent on their employer, and less on the government, for work-family arrangements (Den Dulk, 1999). Again, at second birth the effects are virtually absent.

Finally, we see that there is indeed a structural shift in transition patterns over time. The results indicate that for recent years, mothers in the Netherlands show a lower probability of adopting the YN- and the NN-pattern, and a higher probability of adopting the YY-pattern around first birth. In Germany, the more recent the birth, the greater the probability is that the woman will follow the YN-pattern, and the lower the probability of following the YY-pattern. In the UK, we see an increase in the NY-pattern as more women tend to enter the labour market shortly after childbirth. These same shifts over time are observed around the second birth. Especially for Germany, this may look a bit surprising. As more women choose the YN-pattern at the first birth, we expect a greater number to be in the NN-category at second birth. In our analysis of the transitions around second childbirth there are more women who worked before the second child than we would have expected, based on the analyses of the transitions around first childbirth. This may be due to a sample selection effect because some women had their first child before the start of the panels used.

\section{Institutional changes in the Netherlands, Germany and the UK}

The estimation results show a trend in the Netherlands and the UK towards women's higher labour market participation after childbirth, and a trend towards lower participation after childbirth in Germany. This change in behaviour can perhaps be explained by changes in the social and institutional context in which women make their decisions. Over the last 20 years, social norms have changed and as a result of increased female labour market participation, acceptance of working mothers has increased. This, in turn, leads to a higher proportion of working women. Partly to facilitate these changes in society and partly as a result of these changes, institutions change too.

The remaining question concerns whether there are changes that can explain the different trends in transition patterns. To a certain extent, this question can be answered affirmatively. In the Netherlands, there have been changes in the tax system that made the system more individually based, inducing more women to engage in paid work (Grift, 1998; Gustafsson, 1992; Vlasblom et al., 
2001). Also, in recent years, expenses related to formal childcare have been considered deductible (within certain boundaries). During the 1990s maternity leave arrangements, both legal and those supplied by employers, were extended considerably (Den Dulk, 1999, 2001). From 1997 onwards, parental leave could be taken in a flexible, part-time way. Finally, there was a large increase in childcare facilities and a decrease in costs of these facilities for many workers. In 1991 almost no professional childcare existed. During the next 10 years, the number of day care places for children aged 0-4 years more than doubled, while the number of places for children of primary school age (5-12 years) grew even faster. The actual coverage is now between 20 and 25 percent for children from 0-4 years old and about 10 percent for children from 5-12 years old.

In the UK, over this period the rights and protection of working mothers also increased steadily. Although some of the major changes took place outside our observation period, within this period there was a steady increase in maternity leave rights. The period of leave that could be taken, as well as the payment during leave, became more generous towards mothers (see, for an overview, Gregg et al., 2003). Besides, the taxation system was transformed into an individual system in 1991, including the introduction of individual, non-transferable allowances. This may explain the women's increased return to the labour market in later years. The UK system does not in principle favour parents by means of child allowances and, during the 1990 s, the family subsidy in the tax system decreased, resulting in children representing a higher cost (Sainsbury, 1999). Gregg et al. show that the changes in the institutional system in the UK did change the labour supply behaviour of mothers over the period 1974 to 2000. Our results do not contradict a higher tendency to return to work after a longer interruption. The use of the leave period of 13 weeks is within our 6-12-month spell, and is therefore not picked up by our model. The UK has progressively introduced more generous provisions for parental leave since 1998. Also, in more recent years, a legal right to part-time work and protection for part-time workers was introduced, which further increased the possibilities for women to combine paid work and motherhood. It should be noted that these institutional changes took effect at the very end of and outside the observation period.

In Germany there seems to have been a trend in the direction of a more 'conservative' view on the role of mothers. The German tax system favours households with children. In this way, the tax system lessens the need for a second income in the household and thus favours the option of becoming a singleearner household. This tax reduction for households is large and increased during the period 1985 to 1996 (Sainsbury, 1999). Moreover, Germany has a relatively generous system of parental leave. In 1986 a so-called period of Mutterschutz (Mother protection) of 10 months was introduced. In 1992 the period of Mutterschutz was extended to 24 months and in 1993 to 36 months. There is a tendency for German women to use the full extent of Mutterschutz. In other words, the period young mothers are out of the labour market increases with the extension of the job-protection period. The percentage of 
women who eventually return to the labour market decreased as the period of Mutterschutz increased (Ondrich et al., 1996, 2003). In principle, the father is entitled to part of the parental leave, but in practice only women take it up. The changes in the tax system and in the leave system strongly support the traditional one-earner, breadwinner households. As a result, it does not come as a surprise that for recent birth cohorts a larger percentage of women have decided to leave the labour market and opt for full-time motherhood.

\section{Conclusions}

Numerous studies have pointed out that there are relations between female labour market participation and family career. Using data for the Netherlands, Germany and the UK over the last 20 years we have demonstrated that these interdependencies are strong. Women with children tend to participate less in paid work than those without children. Women who plan to have children show different behaviour on the labour market, even before the birth of the first child. A number of patterns in labour supply can be distinguished. However, most patterns can be characterized by the fact that women tend to lower their participation and their hours of work with each child born.

We showed in this article that these patterns differ between women, depending on their human capital. Women with more human capital tend to have higher participation rates during all stages of their life cycle and family formation than women with less. Choices made with respect to the timing and number of children have a large effect on female economic independence. Policies should not be aimed at general measures, but should be more targeted on subgroups of women, for whom the combination of work and childcare is now almost impossible.

Comparing the three countries, we showed that the differences in patterns chosen between women of various educational backgrounds are roughly comparable. One of the major differences seems to be that over the period considered between 1980 to 2000, in the Netherlands there was a trend towards uninterrupted careers, while during the same period in Germany there seemed to be a trend towards leaving the labour market at childbirth. These differences may be partly attributed to changes in the institutional context. In the Netherlands, and to a lesser extent in the UK, the system was changed with the aim of increasing female participation rates. Based on the idea that women ought to be economically independent, a number of changes were made, one of which is the huge increase in the availability and affordability of day care. This, together with a change in social norms, resulted in an increase in female participation rates and a reduction in 'drop-out' rates at childbirth. In the same period in Germany there have been several reforms and adjustments in tax deductions with respect to children and in the system of maternity leave. All of these changes made full-time motherhood relatively cheap compared to combining work and family. Therefore, we are not surprised to find that the number 
of women who do not leave the labour market, or do not return to work shortly after birth, has declined during this period.

\section{Acknowledgement}

This research is part of the research programme 'Life courses, transitions and the combination of labour and care', financed by NWO (014-21-070-prog.d). This article also benefits from research financed by the European Union as part of the research project Female Employment and Fertility in National Institutional Contexts (FENICs), with contributions from the Universities of Nanterre, Bielefeld, Erlangen, Barcelona (Autonoma), Utrecht and Warwick (http://www.warwick. ac.uk/ier/fenics/index.html). We thank the members of this project, especially HansPeter Blossfeld and Peter Elias, for their helpful comments on earlier versions.

\section{References}

Anxo, D., Stancanelli, E. and Storrie, D. (2000) 'Transitions between Different Working-Time Arrangements: A Comparison of Sweden and the Netherlands', in J. O'Reilly, I. Cebrian and M. Lallement (eds) Working-Time Changes, Social Integration Through Transitional Labour Markets, pp. 93-131. Cheltenham: Edward Elgar.

Becker, G.S. (1965) 'A Theory of the Allocation of Time', The Economic Journal 75(299): 493-517.

Blossfeld, H.-P. and Huinink, J. (1991) 'Human Capital Investments or Norms of Role Transition? How Women's Schooling and Career Affect the Process of Family Formation', American Journal of Sociology 97(1): 143-68.

Bothfeld, S. and O'Reilly, J. (2000) 'Moving Up or Moving Out? Transitions through Part-time Employment in Britain and Germany', in J. O'Reilly, I. Cebrian and M. Lallement (eds) Working-Time Changes, Social Integration Through Transitional Labour Markets, pp. 132-72. Cheltenham: Edward Elgar.

Crompton, R. and Harris, F. (1998a) 'Explaining Women's Employment Patterns: "Orientations to Work" Revisited', The British Journal of Sociology 49(1): 118-36.

Crompton, R. and Harris, F. (1998b) 'A Reply to Hakim', The British Journal of Sociology 49(1): 144-9.

De Jong, A. and De Olde, C.P. (1994) Hoe ouders het werk delen: onderzoek naar de totstandkoming van de verdeling van het betaalde werk en het werk thuis tussen partners met jonge kinderen. The Hague: VUGA.

Den Dulk, L. (1999) 'Work-Family Arrangements in the Netherlands: The Role of Employers', in L. Den Dulk, A. Van Doorne-Huiskes and J.J. Schippers (eds) Work-Family Arrangements in Europe, pp. 21-40. Amsterdam: Thela Thesis.

Den Dulk, L. (2001) Work-family Arrangements in Organisations. A CrossNational Study in The Netherlands, Italy, The UK and Sweden. Amsterdam: Rosenberg Publishers. 
Gregg, P., Gutiérrez-Domènech, M. and Waldfogel, J. (2003) The Employment of Married Mothers in Great Britain: 1974-2000. Working Paper CEPDP0596, Centre for Economic Performance, LSE, London.

Grift, Y.K. (1998) 'Female Labour Supply, the Influence of Taxes and Social Premiums', PhD Thesis, Utrecht University, Utrecht.

Gustafsson, S.S. (1992) 'Separate Taxation and Married Women's Labor Supply. A Comparison of West Germany and Sweden', Journal of Population Economics 5: 61-85.

Gustafsson, S.S., Wetzels, C.M.M.P., Vlasblom, J.D. and Dex, S. (1996) 'Women’s Labor Force Transitions in Connection with Childbirth: A Panel Data Comparison between Germany, Sweden and Great Britain', Journal of Population Economics 9(3): 223-46.

Hakim, C. (1995) 'Five Feminist Myths about Women's Employment', The British Journal of Sociology 46(3): 429-55.

Hakim, C. (1996) 'Labour Mobility and Employment Stability: Rhetoric and Reality on the Sex Differential in Labour-Market Behaviour', European Sociological Review 12(1): 1-31.

Hakim, C. (1998) 'Developing a Sociology for the Twenty-First Century: Preference Theory', The British Journal of Sociology 49(1): 137-43.

Hakim, C. (2000) Work-lifestyle Choices in the 21st Century: Preference Theory. Oxford: Oxford University Press.

Hakim, C. (2003) Models of the Family in Modern Societies: Ideals and Realities. Aldershot: Ashgate Publishing Limited.

Hendrickx, J., Bernasco, W. and De Graaf, P.M. (2001) 'Couples' Labour-Market Participation in the Netherlands', in H.-P. Blossfeld and S. Drobnic (eds) Careers of Couples in Contemporary Societies, From Male Breadwinner to Dual Earner Families, pp. 77-97. New York: Oxford University Press.

Joshi, H., Macran, S. and Dex, S. (1996) 'Employment after Childbearing and Women's Subsequent Labour Force Participation: Evidence from the British 1958 Birth Cohort', Journal of Population Economics 9(3): 325-48.

Koopmans, I. and Schippers, J.J. (2003) 'Welfare State Arrangements and the Reconciliation of Work and Family Life: An International Comparison', 6th Conference of the European Sociological Association (ESA): Ageing Society, New Sociology, Murcia, Spain, 23-26 September.

Lommerud, K.E. and Vagstad, S. (2000) Mommy Tracks and Public Policy: On SelfFulfilling Prophecies and Gender Gaps in Promotion, CEPR Discussion Papers: 2378.

Marks, G. and Houston, D.M. (2002) 'Attitudes Towards Work and Motherhood Held by Working and Non-working Mothers', Work, Employment and Society 16(3): 523-36.

Mertens, E.H.M. (1998) 'ÇLoopbaanonderbrekingen en kinderen: gevolgen voor de beloning van vrouwen', $\mathrm{PhD}$ Thesis, Utrecht University, Utrecht.

Ondrich, J., Spiess, C.K. and Yang, Q. (1996) 'Barefoot and in a German Kitchen: Federal Parental Leave and Benefit Policy and the Return to Work after Childbirth in Germany', Journal of Population Economics 9(3): 247-66.

Ondrich, J., Spiess, C.K., Yang, Q. and Wagner, G. (2003) 'The Liberalization of Maternity Leave Policy and the Return to Work after Childbirth in Germany', Review of Economics of the Household 1: 77-110. 
Portela, M. (2001) 'Measuring Skill: A Multi-dimensional Index', Economics Letters 72: 27-32.

Roman, A. and Schippers, J.J. (2005) To Work or Not to Work: A Vital Life Course Decision and How it Affects Labor Careers. Results from Dutch Panel Data 1990-2001. OSA-publication A212, Institute for Labour Studies, Tilburg.

Sainsbury, D. (1999) 'Taxation, Family Responsibilities and Employment', in D. Sainsbury (ed.) Gender and Welfare State Regimes, pp. 185-209. Oxford: Oxford University Press.

Van der Lippe, T. and Siegers, J.J. (1994) 'Division of Household and Paid Labour between Partners: Effects of Relative Wage Rates and Social Norms', Kyklos 47(1): 109-36.

Vendrik, M.C.M. (1993) 'Collective Habits and Social Norms in Labour Supply: From Micromotives to Macrobehaviour', PhD Thesis, University of Limburg, Maastricht.

Vendrik, M.C.M. (2003) 'Dynamics of a Household Norm in Female Labour Supply', Journal of Economic Dynamics \& Control 27(5): 823-41.

Vlasblom, J.D., De Gijsel, P.P. and Siegers, J.J. (2001) 'Taxes, Female Labour Supply and Household Income: Differences between the Netherlands and the Federal Republic of Germany', Applied Economics, 33(6): 735-44.

Walsh, J. (1999) 'Myths and Counter-Myths: An Analysis of Part-time Female Employees and their Orientations to Work and Working Hours', Work, Employment and Society 13(2): 179-203.

Walters, S. (2005) 'Making the Best of a Bad Job? Female Part-Timers' Orientations and Attitudes to Work', Gender, Work and Organization 12(3): 193-216.

Warren, T. (2004) 'Working Part-time: Achieving a Successful "Work-Life" Balance?', The British Journal of Sociology 55(1): 99-122.

Wetzels, C.M.M.P. (1999) 'Squeezing Birth into Working Life, Household Panel Data Analyses Comparing Germany, Great-Britain, Sweden and The Netherlands', PhD Thesis, University of Amsterdam, Amsterdam.

\section{Jan Dirk Vlasblom}

Jan Dirk Vlasblom is Senior Researcher at the Utrecht School of Economics, Utrecht University. He is currently participating in the research programme 'Life courses, transitions and the combination of labour and care'.

Address: Utrecht School of Economics, Vredenburg 138, 35। I BG Utrecht, The Netherlands.

E-mail: J.Vlasblom@econ.uu.nl 


\section{Joop Schippers}

Joop Schippers is Professor of Labour Economics and the Economics of Equal Opportunity at Utrecht University and programme director at the Institute of Labour Studies (OSA) in Tilburg. He coordinates the research programme 'Life courses, transitions and the combination of labour and care' and several projects on older workers. $\mathrm{He}$ is a member of the Netherlands Audit Committee on Gender Mainstreaming.

Address: Utrecht School of Economics, Vredenburg 138, 35। I BG Utrecht, The Netherlands.

Date submitted October 2004

Date accepted August 2005 